EESTI NSV TEADUSTE AKADEEMIA TOIMETISED. 27. KOIDE GEOLOOGIA, 1978, NR. 3

ИЗВЕСТИЯ АКАДЕМИИ НАУК ЭСТОНСКОИ ССР. ТОМ 27

ГЕОЛОГИЯ, 1978, № 3

\title{
РЕЗУЛЬТАТЫ ИНСТРУМЕНТАЛЬНЫХ СЕЙСМОЛОГИЧЕСКИХ ИССЛЕДОВАНИЙ В ЭПИЦЕНТРАЛЬНОЙ ЗОНЕ ОСМУССААРСКОГО ЗЕМЛЕТРЯСЕНИЯ
}

В период 1/XI-9/XII 1976 г. в эпицентральной зоне шестибалльного Эстонского (Осмуссаарского) землетрясения 25/X 1976 г. были проведены детальные сейсмические наблюдения с целью локализации афтершоков и определения глубинного строения земной коры по сейсмологическим данным. Работы выполнены Всесоюзным геологическим институтом Мингео СССР (ВСЕГЕИ) совместно с Институтом геологии АН ЭССР.

Использовались высокочувствительные автоматические сейсмические станции магнитной записи АСС-3 («Черепаха»), которые по своим основным параметрам относятся к типу станций «Земля» (Мозженко, 1961). Колебания почвы регистрировались сейсмоприемниками НСП-3 с частотой собственных колебаний $1 \Gamma u$ (один вертикальный и два горизонталь-

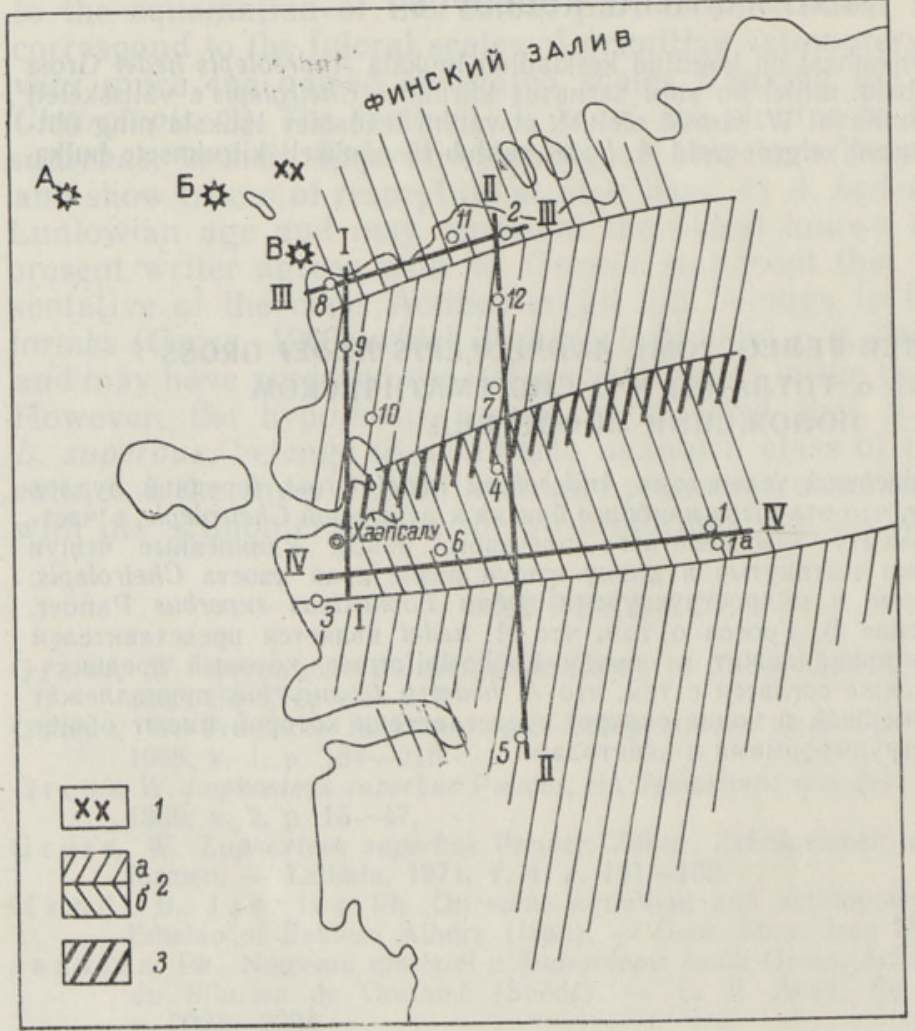

Рис. 1. Расположение стоянок сейсмических станций ACC-3 (112) и эпицентров землетрясений $25 / \mathrm{X} 1976$ г. по данным $\mathrm{ECCH}(A)$, финских (Б) и шведских (B) станций, a также сводных профилей и элементов глубинного строения. I-IV - линии глубинных сейсмических разрезов, 1 - афтершоки, 2 - мощность земной коры $42-44$ км (a), 45-47 км (б), 3 - предполагаемая по МОВЗ зона глубинного разлома. 
ных прибора с ориентировкой осей максимальной чувствительности в магнитных азимутах С $30^{\circ}$ и ЮB $120^{\circ}$ ). Служба времени обеспечивалась кварцевыми часами с точностью $\pm 0,1$ сек. Съем магнитной пленки на станциях записи производился один раз в пять суток. Воспроизведение обзорных и детальных сейсмограмм осуществлялось на станции ВСС-12, входящей в станцию «Черепаха». Детальные (рабочие) сейсмограммы записывались на осциллографную бумагу с использованием четырех каналов на каждую из трех компонент записи (один канал открытый, а три с фильтрацией колебаний). Коэффициенты трансформации частот при воспроизведении равны 25 и 50. Скорость движения фотобумаги (осциллограф Н-100-МЧ) $10-25$ мм/сек позволяет отсчитывать на ленте разности моментов прихода волн с точностью $\pm 0,05-0,1$ сек.

В работе использовалось одновременно 4-5 станций записи АСС-3, проводивших непрерывную круглосуточную регистрацию сейсмических явлений со скоростью протяжки магнитной ленты 1 мм/сек. Стоянки сейсмических станций (рис. 1) расположены на расстоянии 14-70 км от эпицентра землетрясения, в основном в пределах Хаапсалуского района Эстонской ССР. Сейсмоприемники устанавливались в ямы глубиной $\sim 1 \mu$, по возможности на выходах коренных пород силурийского и ордовикского возрастов. Под некоторыми станциями $(4,7,8$ и другими) мощность четвертичных и современных отложений достигала $10-20 \mathrm{~m}$. На стоянках 2 , 3 и 8 наблюдения проводились 19-23 суток (самые длительные), на остальных - в среднем в течение 5-10 суток, что было вызвано необходимостью перемещения станций с целью составления

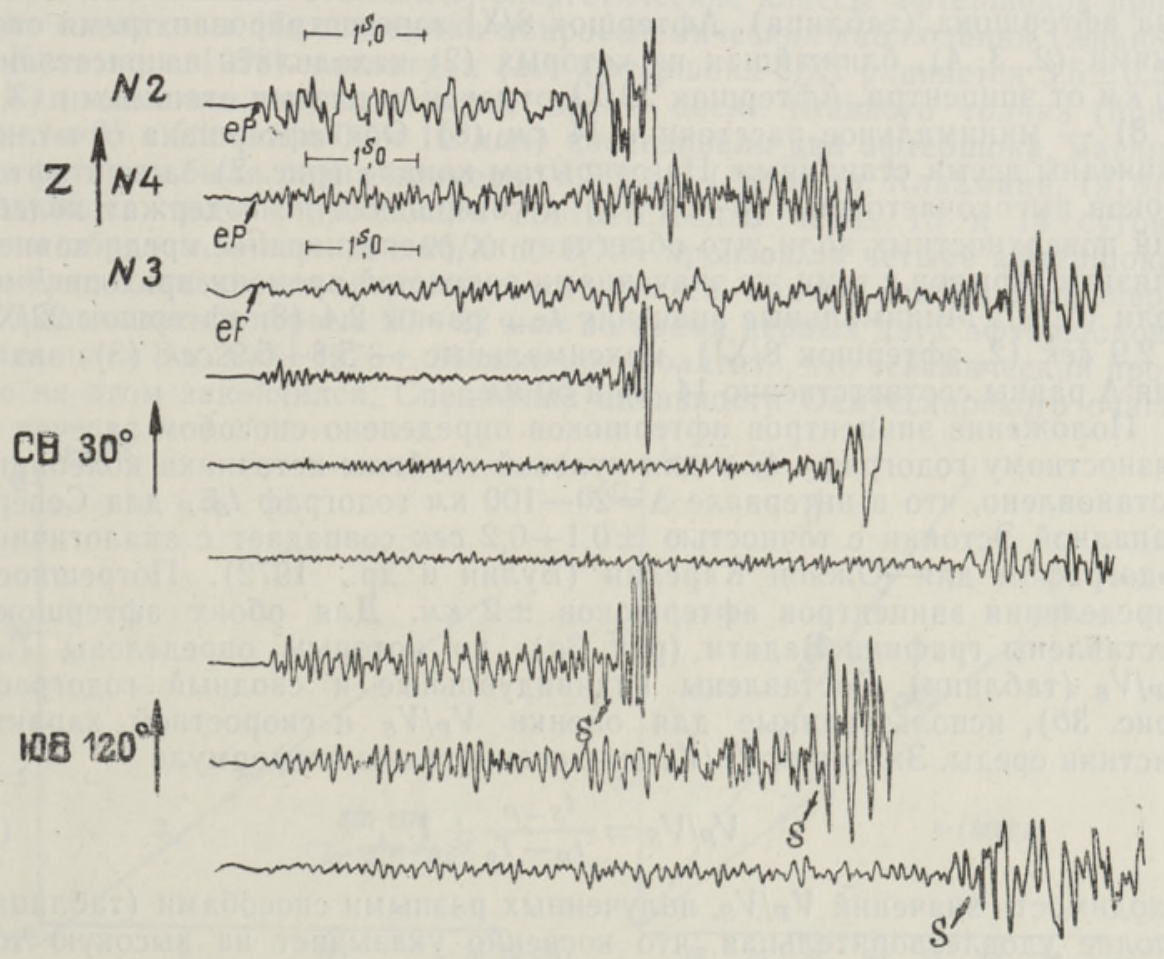

Рис. 2. Сводная сейсмограмма начальных участков записи афтершока 8/XI $1976 \mathrm{r}$. для открытого канала по трем компонентам. Увеличение компонентов разных станций различное $\left(1^{S}, 0\right.$ - масштаб времени). Расположение стоянок $2,3,4$ см. на рис. 1 . 
Основные параметры афтершоков

\begin{tabular}{|c|c|c|c|}
\hline \multirow{2}{*}{ Дата } & \multirow{2}{*}{$\begin{array}{c}\text { Время в очаге по } \\
\text { Гринвичу } T_{0}\end{array}$} & \multicolumn{2}{|c|}{ Координаты эпицентра } \\
\hline & & шнрота & долгота \\
\hline
\end{tabular}

$\begin{array}{rllll}8 / \mathrm{XI} & 10 \text { ч } 17 \text { мин } 0,7 \pm 0,5 \text { сек } & 59^{\circ} 19^{\prime} 7^{\prime \prime} & 23^{\circ} 28^{\prime} 5^{\prime \prime} \\ 22 / \mathrm{XI} & 15 \text { ч } 13 \text { мин } 42,5 \pm 0,5 \text { сек } & 59^{\circ} 19^{\prime} 5^{\prime \prime} & 23^{\circ} 25^{\prime} 4^{\prime \prime}\end{array}$

** Данные станции 8 не учитывались.

разрезов вдоль профилей по данным MOBЗ (метод обменных волн землетрясений).

За период наблюдений продолжительностью 38 суток пятью или одной-четырьмя станциями зарегистрировано более 70 далеких землетрясений, эпицентры которых находились на расстоянии $\Delta=17-140^{\circ}$ (1800-16000 км), и более 100 взрывов с карьеров и шахт Эстонской ССР, Ленинградской области и других районов $(\Delta \leqslant 500 \kappa м)$. Основное число зарегистрированных землетрясений произошло в Тихоокеанском сейсмоактивном поясе (Курило-Камчатская зона, Япония, Филиппины, о-ва Кармадек, Тонга и др.), а также в Турции, Иране и на Памире. Наиболее отчетливые записи продольных $(P)$ и поперечных $(S)$ волн получены с карьеров Харку, Вяо и Маарду.

$\mathrm{C}$ е й с и и е с к а я а к и в н о с т ь. За время исследований выявлены два афтершока (таблица). Афтершок 8/XI зарегистрирован тремя станциями $(2,3,4)$, ближайшая из которых (2) находилась на расстоянии $26 \kappa м$ от эпицентра. Афтершок $22 / \mathrm{XI}$ отмечен четырьмя станциями $(3,6$, $7,8)$ - минимальное расстояние 14 км (8). Оба афтершока отчетливо записаны всеми станциями. На открытом канале (рис. 2) записи афтершоков высокочастотные $(8-20 \Gamma u)$ и совершенно не содержат колебаний поверхностных волн, что облегчает их распознавание среди записей близких взрывов с теми же значениями разностей времени прихода $P$ и $S$ волн $\left(t_{\mathrm{S}-P}\right)$. Минимальные значения $t_{\mathrm{S}-P}$ равны 2,4 (8, афтершок $\left.22 / \mathrm{XI}\right)$ и 2,9 сек (2, афтершок 8/XI), максимальные - 5,8-5,9 сек (3); значения $\Delta$ равны соответственно 14,26 и 50 км.

Положение эпицентров афтершоков определено способом засечек по разностному годографу $t_{\mathrm{S}-\mathrm{P}}$ для нулевой глубины источника колебаний. Установлено, что в интервале $\Delta=20-100 \mathrm{kM}$ годограф $t_{\mathrm{S}-P}$ для СевероЗападной Эстонии с точностью $\pm 0,1-0,2$ сек совпадает с аналогичным годографом для Южной Карелии (Булин и др., 1972). Погрешность определения эпицентров афтершоков $\pm 2 \kappa$. Для обоих афтершоков составлены графики Вадати (рис. $3 a$ ), по которым определены $T_{0}$ и $V_{P} / V_{S}$ (таблица). Составлены индивидуальные и сводный годографы (рис. Зб), использованные для оценки $V_{P} / V_{S}$ и скоростной характеристики среды. Значения $V_{P} / V_{S}$ вычислены также по формуле

$$
V_{P} / V_{S}=\frac{t_{S-P}}{t_{P}-T_{0}}+1
$$

Сходимость значений $V_{P} / V_{\mathrm{S}}$, полученных разными способами (таблица), вполне удовлетворительная, что косвенно указывает на высокую точность определения кинематических характеристик афтершоков.

Эпицентры афтершоков находились в $3-4 \kappa м$ северо-восточнее о-ва Осмуссаар и в пределах погрешности определений совпадали. От эпицентров основного толчка, вычисленных по данным финских и шведских 


\section{Осмуссаарского землетрясения}

\begin{tabular}{|c|c|c|c|c|c|}
\hline \multirow{3}{*}{$\begin{array}{c}\text { Глубина } \\
\text { очага } H \text {, } \\
\kappa м\end{array}$} & \multirow{2}{*}{\multicolumn{2}{|c|}{$\begin{array}{c}\text { Значение кажу- } \\
\text { щейся скорости } \\
V_{P, S \text { на годографе, }}^{*} \\
\text { км/сек }\end{array}$}} & \multicolumn{3}{|c|}{ Значение $V_{P} / V_{S}$} \\
\hline & & & \multirow{2}{*}{$\begin{array}{l}\text { по гра'- } \\
\text { фику } \\
\text { Вадати }\end{array}$} & \multirow{2}{*}{$\begin{array}{c}\text { по отношению кажу- } \\
\text { щейся скорости } \\
V_{P}^{*} / V_{S}^{*}\end{array}$} & \multirow{2}{*}{$\begin{array}{l}\text { по формуле } \\
\text { (1) }\end{array}$} \\
\hline & $P$ & $S$ & & & \\
\hline $0-13$ & 6,6 & 3,7 & 1,76 & $1,78 \pm 0,03$ & $1,76 \pm 0,02$ \\
\hline $13 \pm 2$ & 6,75 & 3,75 & 1,77 & $1,79 \pm 0,03$ & $1,79^{* *} \pm 0,03$ \\
\hline
\end{tabular}

станций, афтершоки находились на расстоянии 7-9 км. Все эпицентры (два варианта для первого толчка и афтершоки) образуют треугольник, в средней части которого находится о-в Осмуссаар. Таким образом, с достаточной для практики точностью за эпицентр землетрясения $25 / \mathrm{X}$ 1976 г. можно принять о-в Осмуссаар, что полностью подтвердил анализ макросейсмических данных (Ананьин, Клааманн, 1978).

Глубина гипоцентра второго афтершока, вычисленная способом перебора скоростных разрезов при заданном положении эпицентра, составила $13 \pm 2$ км. Для афтершока 8/XI можно указать лишь вероятный интервал глубины гипоцентра $(0-13$, ближе к 5-10 км). О меньшей глубине афтершока 8/XI косвенно свидетельствуют данные длительности сейсмических колебаний и значения $V_{P, s}$ (таблица).

Судя по записям станции 3 , энергетические классы афтершоков примерно одинаковы. На основании макросейсмических наблюдений (Ананьин, Клааманн, 1978) магнитуда $(M)$ афтершока $8 /$ XI равняется $3,5 \pm 0,5$.

Как известно, через некоторое время после главного толчка (примерно в 08 ч 50 мин и 09 ч 10 мин) последовали два афтершока, магнитуда которых была равна примерно 3,5 и 3,0 (Ананьин, Клааманн, 1978). Следующие толчки произошли соответственно через 13 и 14 суток. Таким образом, в период с 25/X по 8/XII произошли четыре афтершока примерно одинакового энергетического класса, причем наибольшая энергия выделилась в первые 20-22 мин во время первых двух афтершоков, а остальная 8 и 22/XI 1976 г. Можно предполагать, что сейсмический процесс на этом закончился. Специфика активности Осмуссаарского очага
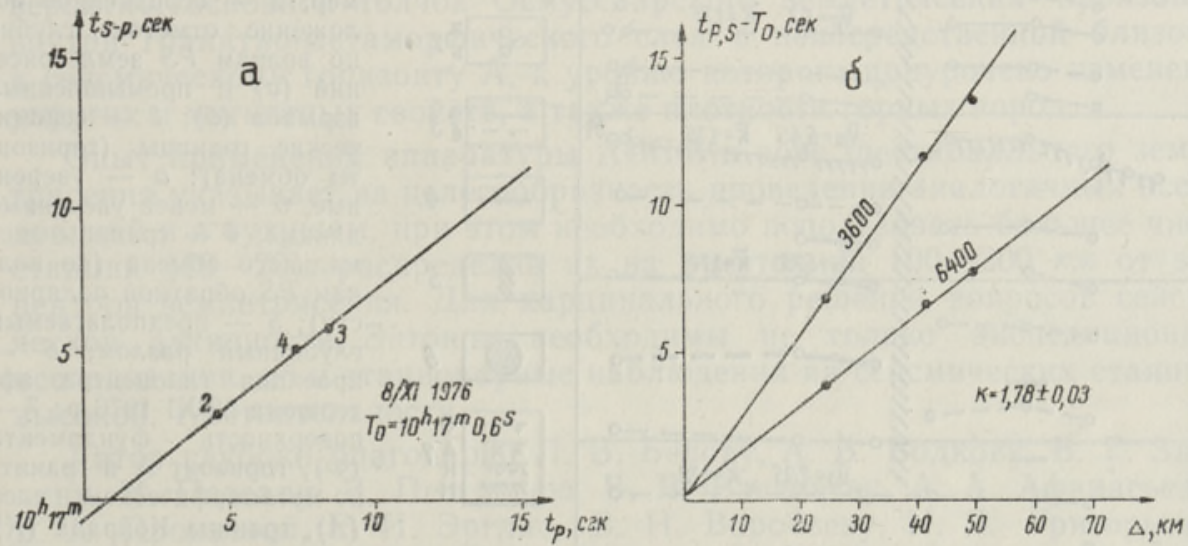

Рис. 3. График Вадати (a) для афтершока 8/XI 1976 г. (точки соответствуют номерам стоянок станций - см. рис. 1) и годограф сейсмическнх волн (б) по данным афтершока 8/XI 1976 г. Цифры на годографе - значения кажущейся скорости

$\left(V^{*}\right) P$ и $S$ волн, $м /$ сек. 
заключается не только в малом числе афтершоков, но и в том, что все они были близки по выделившейся сейсмической энергии.

Гл убиннное строени е. Характеристика глубинного строения получена по наблюдениям обменных преломленных (проходящих) волн $P S$ в 13 пунктах (рис. 1). Основную информацию дают записи далеких землетрясений; по волнам $P S$ от взрывов освещается в основном верхняя часть разреза до глубины $20-25 \kappa$. Выделение волн $P S$, определение времени их запаздывания относительно продольной волны $\left(\Delta t_{P S-P}\right)$, вычисление глубин и корреляции между границами преломления (обмена) произведены в соответствии с известными критериями (Булин, 1976 и др.). Значения средней скорости волн $\bar{V}_{P}, \bar{V}_{S}$ в платформенном чехле взяты по данным Н. К. Озолинь (1974) и по результатам сейсмокаротажа Даниловской скважины (данные А. Г. Шехтмана, 1972; ВНИИгеофизика). При глубине до фундамента $\sim 300$ м $\bar{V}_{P} \approx 2,6-2,7, \bar{V}_{S} \approx 0,7-$ $0,8 \kappa м / с е к$. Для вычисления глубоких границ обмена использован скоростной разрез Балтийского щита (Литвиненко, 1962), при этом расчет глубин произведен по редуцированным значениям $\Delta t_{P S-P}$, приведенным к значениям поверхности фундамента. Величина редукции составляла 0,2 и 0,3 сек при глубине фундамента соответственно 0,2 и $0,3-0,4 \kappa м$.

Глубинное строение эпицентральной зоны иллюстрируется разрезом (рис. 4) и схемой (рис. 1). Разрезы по другим профилям будут описаны позже (Булин, 1978). Подобно другим разрезам, в разрезе профиля II-II маркирующими для МОВЗ являются следующие границы обмена: а) поверхность кристаллического фундамента $(\Phi) \quad\left(\Delta t_{P S-P}=0,2-0,35\right.$ сек, $H=0,2-0,4 \kappa M)$, б) горизонт A $(A)\left(\Delta t_{P S-P}=1,8-2,2\right.$ сек, $\left.H=12-16 \kappa м\right)$ внутри гранитно-метаморфического слоя, являющийся одной из наиболее

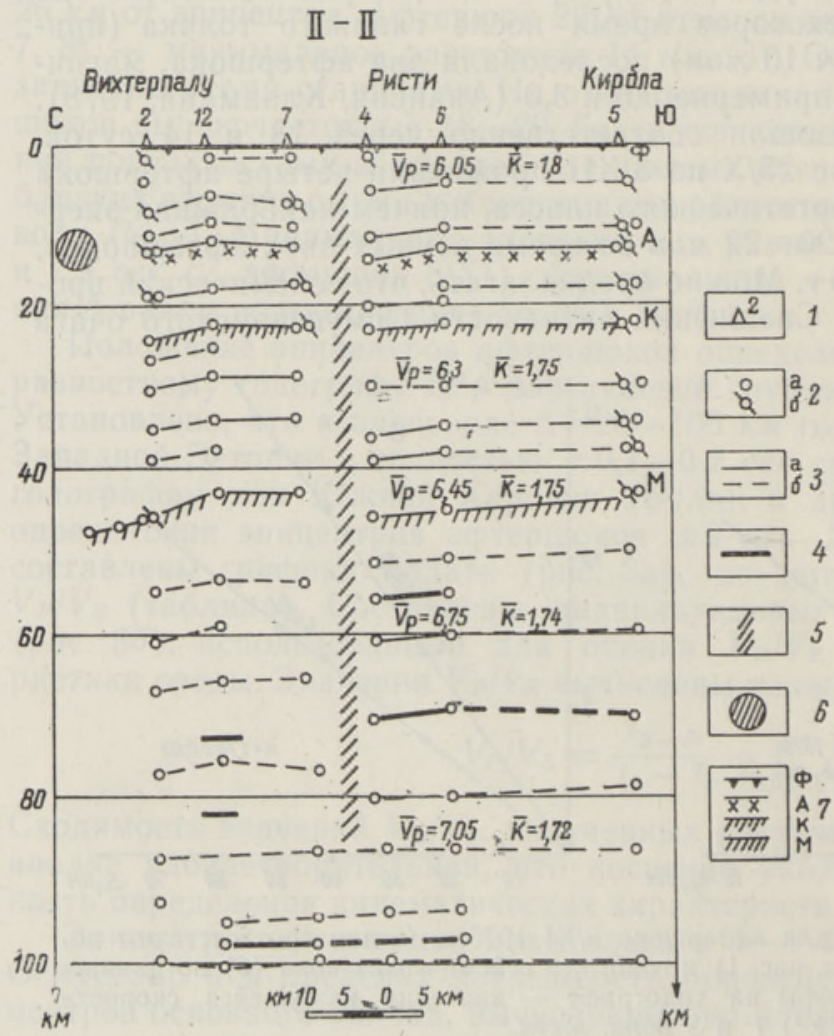

Рис. 4. Ооредненный глубинный сейсмнческий разрез вдоль линии II-II Вихтерпалу-Кирбла (см. рис. 1) - по наблюдениям обменных волн $P S$ далеких землетрясений и промышленных взрывов: 1 - сейсмическая станция и ее номер; 2 - осредненное положение отметок глубин по волнам $P S$ землетрясений $(a)$ и промышленных взрывов (б); 3 - сейсмические границы (горизонты обмена): $a$ - уверенные, 6 - менее уверенные данные; 4 - границы аномального обмена (по волнам $P S$ обратной полярности); 5 - предполагаемый глубинный разлом; 6 . проекция гипоцентра афтершока 22/XI 1976 г.; 7 поверхность фундамента $(\Phi)$, горизонт А в гранитно-метаморфическом слое $(A)$, праница Конрада $(K)$ и поверхность Мохоровичича $(M) ; \bar{V}_{P}-$ средняя скорость волн $P$ (км/сек), $\bar{K}$ - среднее значение параметра $K$, равное $\bar{V}_{P} / \bar{V}_{\boldsymbol{s}}$. 
четких сейсмических границ на Балтийском щите (Булин и др., 1972) и всей Евразии (Булин, 1974), в) граница Мохоровичича $(M)\left(\Delta t_{P S-P}=\right.$ $=5,0-6,2$ сек, $H=42-47 \kappa м)$. Поверхность Конрада $(K)$ фиксируется менее устойчиво и выделена в разрезе условно, по аналогии с $K$ для других районов СССР.

Земная кора и верхняя часть мантии до глубины $100 \kappa м$ характеризуются тонкослоистым строением и близконформным расположением сейсмических границ. В южном блоке (Ристи-Кирбла) отмечается несогласное залегание границы $H \approx 30 \kappa м$ с более глубокими горизонтами «базальтового» слоя. Между станциями 4 и 7 отчетливо фиксируется глубинный разлом, прослеживаемый до $H \approx 80$ км. Нельзя исключать возможности его наклонного положения (наклон к югу под углом $70-80^{\circ}$ ). В интервалах $H \approx 55,70-82$ и $79-99 \kappa м$ сконцентрированы границы аномального обмена, которые могут быть связаны как с наклоном сейсмических границ, так и с наличием зон пониженной скорости сейсмических волн. Характерно, что второй уровень глубин аномальных границ $(70-82 \kappa м)$ практически совпадает со средним уровнем глубины $(\sim 75 \kappa м)$ проводящего слоя верхней мантии, установленного X. Андра и др. (1974).

Районирование исследованного участка Северо-Западной Эстонии по рельефу границы $M$ (рис. 1) показывает, что здесь можно выделить четыре зоны (блока). В северном блоке (первый), к которому приурочен очаг землетрясения, толщина коры максимальная (45-47, до 48? км по единичным данным). Второй (с севера на юг) и третий (самый южный) блоки отличаются более спокойными формами рельефа границы $M$ и меньшими глубинами ее кровли $(42-44 \kappa м)$ и, вероятно, являются фоновыми для территории Эстонии. Четвертый (Хаапсалуский) блок во многом аналогичен по строению северному.

Гипоцентр афтершока приурочен к уровню горизонта А (рис. 4). Согласно годографу (рис. $3 a$ ), в этом интервале глубин происходит

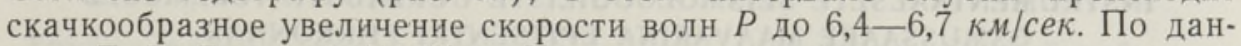
ным Л. В. Булиной (1976), в Хаапсалуском районе нижние кромки намагниченных тел расположены на $H=10-15 \kappa м$, т. е. на уровне горизонта А. Согласно расчетам Е. Ф. Козловой и А. А. Патрушевой (1976), особые точки, характерные для контактовых поверхностей (гравитационные данные), приурочены к глубинам от $9,5-11,5$ до $12,5-14,5 \kappa м$, т. е. также соответствуют глубине афтершока. Таким образом, афтершоки и, вероятно, основной толчок Осмуссаарского землетрясения произошли внутри гранитно-метаморфического слоя в непосредственной близости к сейсмическому горизонту $\mathrm{A}$, к уровню которого приурочено изменение упругих и магнитных свойств, а также плотности горных пород.

Опыт применения аппаратуры АСС-3 в зоне шестибалльного землетрясения указывает на целесообразность проведения аналогичных исследований и в будущем, при этом необходимо использовать большее число станций $(10-20)$, распределив их на расстоянии $100-200 \kappa м$ от эпнцентров землетрясения. Для кардинального решения вопросов сейсмической активности Эстонии необходимы не только экспедиционные исследования, но и стационарные наблюдения на сейсмических станциях высокой чувствительности.

Автор глубоко благодарен Л. В. Белову, А. В. Волкову, В. Г. Забелину, И. Паэсалу, В. Петерселю, В. В. Васильеву, А. А. Афанасьевой; Е. А. Проняевой, Е. И. Эрглис, В. Н. Воробьеву, Н. Я. Григорьевой, А. А. Пастушенко и Б. А. Яшину за помощь при проведении исследований, а также Д. Кальо, Х. Вийдингу, С. В. Егорову и Х. А. Смыслову за хорошую организацию экспедиции.

3 ENSV TA Toimetised. G 31978 


\section{ЛИТЕРАТ У РА}

Ан аньин И. В., Кла ам анн Э. Р. Осмуссаарское (Эстонское) землетрясение 25/Х 1976 г. - В жн.: Землетрясения в СССР в 1976 году. М., 1978, с. 237-249.

Андл а Х., В а хер Р., Побул Э., Юрине И. Результаты магнитотеллурических исследований в Эстонии. - Изв. АН ЭССР, Хим. Геол., 1974, т. 23, № 1, с. 50-53.

Булин Н. К. Глубинное строение Северо-Западной Эстонии по данным МОВ3. Саветская геология, 1978 (в печати).

Бу ли н Н. К. Об одной сейсмической границе в консолидированной земной коре Евразии. - Изв. АН ССОР, Серия геол., 1974, № 8, с. 5-25.

Бул ин Н. К., Афан ась е ва Н. А., Проня ева Е. А. Профильные сейсмологические исследования в южной части Балтийского щита. - Прикладная геофизика, 1972 , вып. 69 , с. $69-81$.

Булин Н. К. Опыт построения глубннных сейсмических разрезов по наблюдениям обменных проходящих волн. - Тр. ВСЕГЕИ. Нов. серия, 1976, т. 225, с. 16-21.

Б улин а Л. В. Характерные черты распределения нижних кромок намагниченных тел на территории СССР. - В кн.: Магнитные аномалии земных глубин. Киев, 1976, c. $137-151$.

Козл в а Е. Ф., П а тр ушев а В. А. Методика и результаты интерпретации гравиметрических материалов для изучения глубинного геологического строения Русской плиты. - Разведочная геофизика, 1976, вып. 72, с. 105-112.

Лит в нненко И. В., Некр а сов а К. А. Особенности глубинного сейсмического зондирования на Балтийском щите. - В кн.: Глубинное сейсмическое зондирование земной коры в СССР. Л., 1962, с. 187-206.

Мозжен ко А. Н. Аппаратура магнитной записи для регистрации землетрясений и удаленных взрывов. - Изв. АН ТуркмССР, Серия физико-техн., химич. и геол. наук, 1961, № 1, с. 33-38.

О зо лин н Н. К. (ред.). Физические свойства пород Балтийской синеклизы. Рига, 1974.

Всесоюзный ордена Ленина

научно-исследовательский геологический институт
Поступила в редакцию 1/VI 1977

\section{N. BULIN}

\section{INSTRUMENTAALSETE SEISMOLOOGILISTE UURIMUSTE TULEMUSED OSMUSSAARE MAAVARINA EPITSENTRI PIIRKONNAS}

Artiklis on esitatud eriti tundlike automaatseismograafide abil 1976. aasta novembrisdetsembris Loode-Eestis sooritatud seismiliste vaatluste tulemused. Registreeriti kaks peatōukele järgnenud järeltōuget, kaugete maavärinate laineid ja tööstuslikke lõhanguid seismiliste võnkumiste sagedusega $1-20 \mathrm{~Hz}$. Määrati kindlaks järeltōugete epitsentrite asukohad ja maakoore süvaehitus neljal profiilil üldpikkusega $160 \mathrm{~km}$. Uurimispiirkonnas on maakoor $42-47 \mathrm{~km}$ paks, Osmussaare maavärina kolle asub $45-47 \mathrm{~km}$ paksuses makkoore plokis.

\section{N. BULIN}

\section{SEISMOLOGICAL INVESTIGATIONS IN THE FOCAL REGION OF THE OSMUSSAAR EARTHQUAKE}

In the interval of time between November 1 and December 9, 1976, seismic survey was carried out in the $4-5$ ball zone of the 6 ball $(M=4.5-4.8$, Richter's scale) Osmussaar (North-West Estonia, Fig. 1) earthquake of October 25, 1976, using highly sensitive equipment synchronously at $4-5$ stations. Seismic waves from two aftershocks have been recorded (Fig. 2). The epicentres, the origin-time at the source and the seismic wave velocities of these aftershocks have been determined (see Table, Fig. 3).

From PS, records of distant earthquakes and mining industrial explosions in the Earth's structure down to the depth of $100 \mathrm{~km}$ have been determined and 4 vertical sections on traverses totalling some $160 \mathrm{~km}$ constructed. One of them is shown in Fig. 4.

The most distinct discontinuities appear at depths of $0.2-0.4 \mathrm{~km}$ (the basement surface), $12-16 \mathrm{~km}$ and $42-47 \mathrm{~km}$ (the Mokhorovichich discontinuity). Four sublatitudinal blocks of the Earth's crust (with the thickness of $42-44$ or $45-47 \mathrm{~km}$ ) have been marked out. The focus of the earthquake lies in the thicker crustal block at the depth of $5-15 \mathrm{~km}$. 